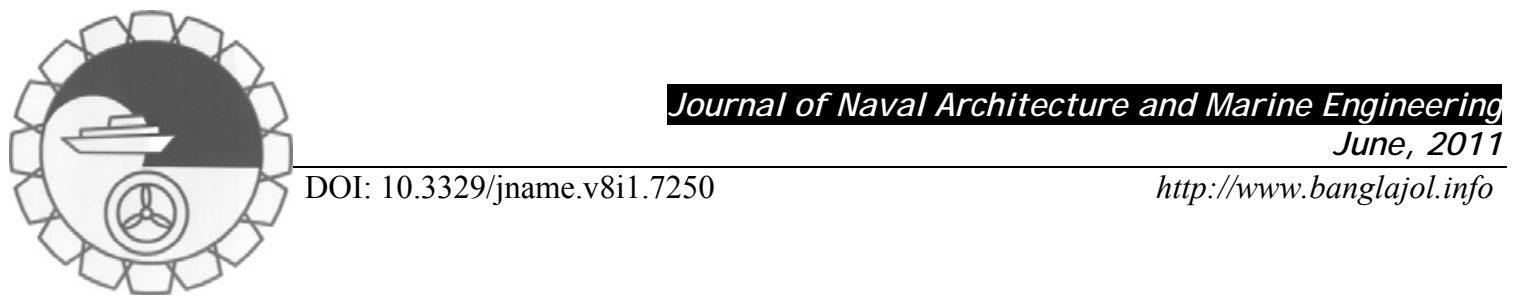

\title{
UNSTEADY DOUBLE-DIFFUSIVE NATURAL CONMECTIVE MHD FLOW ALONG A VERTICAL CYLINDER IN THE PRESENCE OF CHEMCAL REACTION, THERMAL RADIATION AND SORET AND DUFOUR EFFECTS
}

\author{
A. J. Chamkha ${ }^{1}$, M. F. El-Amin ${ }^{2}$ and A. M. Aly ${ }^{3}$
}

${ }^{1}$ Manufacturing Engineering Department, The Public Authority for Applied Education and Training, Shuweikh 70654, Kuwait

${ }^{2}$ Department of Mathematics, Aswan Faculty of Science, South Valley University, Egypt

${ }^{3}$ Department of Mathematics, Faculty of Science, South Valley University, Qena, Egypt

\section{Abstract:}

This work is focused on the numerical solution of unsteady double-diffusive free convective flow along a vertical isothermal cylinder in the presence of a transverse magnetic field, first-order homogeneous chemical reaction, thermal radiation and Soret and Dufour effects. The Rosseland approximation is used to describe the radiative heat flux in the energy equation. The governing equations are formulated and a numerical solution is obtained by using an explicit finite-difference scheme. The solutions at each time step have been found to reach the steady state solution properly. Representative results for the fluid velocity, temperature and solute concentration profiles as well as the local heat and mass transfer rates for various values of the physical parameters are displayed in both graphical and tabular forms

Keywords: Finite-difference solution; MHD; unsteady flow; cylinder; chemical reaction; Soret and Dufour effects; thermal radiation.

\section{NOMENCLATURE}

$B_{0} \quad$ Strength of magnetic field

$C \quad$ Solute concentration

$C_{p} \quad$ Specific heat diffusivity

$C_{s} \quad$ Concentration susceptibility

$D_{m} \quad$ Mass Diffusivity

Du Dufour number

$g \quad$ Acceleration due to gravity

$k_{c} \quad$ Rate of chemical reaction

$k_{T} \quad$ Thermal diffusion ratio

$k^{*} \quad$ Mean absorption coefficient

$N u_{x} \quad$ Nusselt number

Pr Prandtl number

$q_{r} \quad$ Radiative heat flux

$r \quad$ Radial coordinate

$R^{*} \quad$ Radiation parameter

$S_{c} \quad$ Schmidt number

$S h_{x} \quad$ Sherwood number

$\mathrm{Sr} \quad$ Soret number

T Temperature

$t \quad$ Time

$$
\begin{array}{ll}
T_{m} & \text { Mean fluid temperature, } \\
T^{\prime}{ }_{w} & \text { Wall temperature } \\
x & \quad \text { Cartesian coordinate }
\end{array}
$$

\section{Greek Symbols}

$\alpha \quad$ Thermal diffusivity

$\beta_{T} \quad$ Coefficient of thermal expansion

$\beta_{C} \quad$ Coefficient of concentration expansion

$\gamma \quad$ Chemical reaction parameter.

$v \quad$ Kinematics viscosity

$\sigma \quad$ Fluid electrical conductivity

$\sigma_{0} \quad$ Stefan-Boltzmann constant

$\rho \quad$ Density of the fluid

\section{Subscripts}
w Refers to wall condition
$\infty \quad$ Refers to ambient condition
Superscript

' Differentiation with respect to $\eta$ 


\section{Introduction}

In nature, the presence of pure air or water is impossible. Some foreign mass may be present either naturally or mixed with the air or water. Chemical reactions can be classified as either heterogeneous or homogeneous processes. This depends on whether they occur at an interface or as a single phase volume reaction. In wellmixed systems, the reaction is heterogeneous, if it takes place at an interface and homogeneous, if it takes place in solution. In most cases of chemical reactions, the reaction rate depends on the concentration of the species itself. The application of boundary layer techniques to mass transfer has been of considerable assistance in developing the theory of separation processes and chemical kinetics.

The heat and mass transfers simultaneously affecting each other that will cause the cross-diffusion effect. The mass transfer caused by the temperature gradient is called Soret effect and it has been utilized for isotope separation and in a mixture between gases and with very light molecular weight $\left(\mathrm{H}_{2}, \mathrm{He}\right)$ and of medium molecular weight $\left(\mathrm{H}_{2}\right.$, air), while the heat transfer caused by the concentration gradient is called Dufour effect. In addition, the double-diffusive convection is of importance in various fields such as high quality crystal production, oceanography, production of pure medication, solidification of molten alloys, geothermally-heated lakes and magmas. For example the quality of the single crystal produced from the melts is limited by chemical and structural inhomogeneities. The defect generation depends on heat and mass transfer rates during solidification. These fluxes are mainly governed by convective phenomena of the liquid phase during processing. Also the thermal-diffusion and the diffusion-thermo effects are an interesting macroscopically physical phenomenon in fluid mechanics. The effects of thermal diffusion and diffusion thermo on the transport of heat and mass has been developed from the kinetic theory of gases by Chapman and Cowling (1952) and Hirshfelder et al. (1954) explained the phenomena and derived the necessary formulae to calculate the thermaldiffusion coefficient and thermal-diffusion factor for monatomic gases or for polyatomic gas mixtures. Sparrow et al. (1964) studied experimentally the effect of diffusion thermo in stagnation-point flow of air with injection of gases of various molecular weights into the boundary layer. Kfoussias and Williams (1995) studied the effects of thermal-diffusion and diffusion thermo on steady mixed free-forced convective and mass transfer over a vertical flat plate, when the viscosity of the fluid is varies with temperature. Recently, Kandasamy et al. (2005, 2005) studied the heat and mass transfer under a chemical reaction with a heat source. Seddeek (2001) studied the thermal radiation and buoyancy effects on MHD free convection heat generation flow over an accelerating permeable surface with the influence temperature dependent viscosity. Later on, Seddeek and co-workers (2007, 2007, 2007) included the effects chemical reaction, variable viscosity, radiation, variable suction on hydromagnetic convection flow problems. Chamkha and Ben-Nakhi (2008) analyzed the MHD mixed convection flow under radiation interaction along a vertical permeable surface immersed in a porous medium in the presence of Soret and Dufour's effects.

The study of magnetohydrodynamic viscous radiate flows has important industrial, technological and geothermal applications such as high-temperature plasmas, cooling of nuclear reactors, liquid-metal fluids, MHD accelerators, and power-generation systems. Hossain and Takhar (1996) analyzed the effect of radiation using the Rosseland diffusion approximation which leads to non-similar solutions for the forced and free convection flow of an optically dense fluid from vertical surfaces with constant free stream velocity and surface temperature. Hossain et al. (1999) studied the effect of radiation on free convection heat transfer from a porous vertical plate. Duwairi and Damseh $(2004,2004)$ studied the radiation-conduction interaction in free and mixed convection fluid flow for a vertical flat plate in the presence of a magnetic field effect.

There are only few papers in the literature that deal with an analysis of simultaneous heat and mass transfer along a vertical cylinder. Bottemanne (1972) studied such a problem for steady heat and mass flux conditions, both experimentally and theoretically. Chen and Yuh (1980) dealt with steady combined heat and mass transfer effects for both conditions of uniform wall temperature/concentration and uniform heat/mass flux. Heckel et al. (1989) studied the steady free convection along slender vertical cylinders for variable surface heat flux conditions. Chen (1983) investigated the steady free convection from a vertical needle with variable wall heat flux and found that there was significant influence of its shape, size and wall temperature variation upon the flow and heat transfer.

The unsteady natural convection flow over a vertical cylinder with MHD effects has been given some attention in the literature. Ganesan and Rani $(2000,1999)$ studied unsteady free convection MHD flow past a vertical cylinder with heat and mass transfer or with variable heat and mass flux. Ganesan and longathan (2001) studied

Unsteady double-diffusive natural convective MHD flow along a vertical cylinder ...... 
unsteady natural convective flow past a moving vertical cylinder with heat and mass transfer. In the present work, unsteady MHD free convection flow along a vertical isothermal cylinder in the presence of a transverse magnetic field, homogeneous first-order chemical reaction, thermal radiation and Soret and Dufour's effects.

\section{Mathematical Analysis}

Consider unsteady, laminar, boundary layer, two-dimensional double diffusion free convective MHD flow along a vertical cylinder in the presence of chemical reaction, thermal radiation and Soret and Dufour effects. The fluid properties are assumed to be constant and the chemical reaction which takes place in the flow is assumed to be homogeneous and of first order. Far from the cylinder surface, the free stream temperature and concentration are assumed to be constant. Under these assumptions and with the usual Boussinesq approximation, the governing boundary-layer equations that are based on the balance laws of mass, linear momentum, energy and concentration species for this investigation can be written as:

$$
\begin{aligned}
& \frac{\partial}{\partial x}(r u)+\frac{\partial}{\partial r}(r v)=0 \\
& \frac{\partial u}{\partial t^{\prime}}+u \frac{\partial u}{\partial x}+v \frac{\partial u}{\partial r}=\frac{v}{r} \frac{\partial}{\partial r}\left(r \frac{\partial u}{\partial r}\right)+g \beta_{T}\left(T^{\prime}-T_{\infty}^{\prime}\right)+g \beta_{C}\left(C^{\prime}-C_{\infty}^{\prime}\right)-\frac{\sigma B_{0}^{2}}{\rho} u, \\
& \frac{\partial T^{\prime}}{\partial t^{\prime}}+u \frac{\partial T^{\prime}}{\partial x}+v \frac{\partial T^{\prime}}{\partial r}=\frac{\alpha}{r} \frac{\partial}{\partial r}\left(r \frac{\partial T^{\prime}}{\partial r}\right)-\frac{1}{\rho C_{P}} \frac{\partial q_{r}}{\partial r}+\frac{D_{m} k_{T}}{C_{S} C_{P}} \frac{1}{r} \frac{\partial}{\partial r}\left(r \frac{\partial C^{\prime}}{\partial r}\right), \\
& \frac{\partial C^{\prime}}{\partial t^{\prime}}+u \frac{\partial C^{\prime}}{\partial x}+v \frac{\partial C^{\prime}}{\partial r}=\frac{D_{m}}{r} \frac{\partial}{\partial r}\left(r \frac{\partial C^{\prime}}{\partial r}\right)-k_{c}\left(C^{\prime}-C_{\infty}^{\prime}\right)+\frac{D_{m} k_{T}}{T_{m}} \frac{1}{r} \frac{\partial}{\partial r}\left(r \frac{\partial T^{\prime}}{\partial r}\right),
\end{aligned}
$$

where $\mathrm{t}$ is time and $\mathrm{x}$ and $r$ are the Cartesian and radial coordinates, respectively. $\mathrm{u}, \mathrm{v}, T$ and $C$ are the fluid $\mathrm{x}$-component of velocity, $r$-component of velocity, temperature and solute concentration, respectively. $v$ is the fluid kinematic viscosity, $\sigma$ is the fluid electrical conductivity, $B_{0}$ is the strength of magnetic field or magnetic induction, $\rho$ is the fluid density, $\alpha$ is the thermal diffusivity, $C_{P}$ is the specific heat at constant pressure and $q_{r}$ is the radiative heat flux. $k_{c}$ is the rate of chemical reaction, $g$ is the acceleration due to gravity, $\beta_{T}$ is the volumetric coefficient of thermal expansion, $\beta_{C}$ is the volumetric coefficient of concentration expansion. $D_{m}$ is coefficient of mass diffusivity. $T$ and $C$ are the free stream temperature and concentration, respectively. $T_{m}$ is the mean fluid temperature, $k_{T}$ is the thermal diffusion ratio and $\mathrm{C}_{\mathrm{S}}$ is the concentration susceptibility.

The radiative heat flux term is simplified by using the Rosseland approximation (see Sparrow and Cess (1962)) as

$q_{r}=-\frac{4 \sigma_{0}}{3 k^{*}} \frac{\partial T^{4}}{\partial r}$

where $\sigma_{0}$ and $k^{*}$ are Stefan-Boltzmann constant and mean absorption coefficient, respectively. A Taylor series expansion of $T^{4}$ neglecting higher order terms gives

$T^{4}=4 T_{\infty}^{3} T-3 T_{\infty}^{4}$,

Using Equations (5) and (6) in the energy equation (3) obtains

$\frac{\partial T^{\prime}}{\partial t^{\prime}}+u \frac{\partial T^{\prime}}{\partial x}+v \frac{\partial T^{\prime}}{\partial r}=\frac{v}{\operatorname{Pr}}\left(1+\frac{4}{3 R}\right) \frac{1}{r} \frac{\partial}{\partial r}\left(r \frac{\partial T^{\prime}}{\partial r}\right)+\frac{D_{m} k_{T}}{C_{S} C_{P}} \frac{1}{r} \frac{\partial}{\partial r}\left(r \frac{\partial C^{\prime}}{\partial r}\right)$,

where $R^{*}=\frac{k k^{*}}{4 \sigma T_{\infty}^{3}}$ is the radiation parameter.

The proper initial and boundary conditions for this problem are:

$$
\begin{aligned}
& t^{\prime}=0: u=v=0, T^{\prime}=T_{\infty}^{\prime}, C^{\prime}=C_{\infty}^{\prime} \\
& \mathrm{t}>0: \begin{cases}\mathrm{u}=\mathrm{v}=0, \mathrm{~T}^{\prime}=\mathrm{T}_{\infty}^{\prime}, \mathrm{C}^{\prime}=\mathrm{C}_{\infty}^{\prime} & \text { at } \mathrm{x}=0 \\
\mathrm{u}=\mathrm{v}=0, \mathrm{~T}^{\prime}=\mathrm{T}_{\mathrm{w}}^{\prime}, \mathrm{C}^{\prime}=\mathrm{C}_{\mathrm{w}}^{\prime} & \text { at } \mathrm{r}=\mathrm{r}_{0}, \mathrm{x}>0 \\
\mathrm{u}=0, \mathrm{~T}^{\prime}=\mathrm{T}_{\infty}^{\prime}, \mathrm{C}^{\prime}=\mathrm{C}_{\infty}^{\prime} & \text { at } \mathrm{r} \rightarrow \infty, \mathrm{x}>0\end{cases}
\end{aligned}
$$


It is convenient to substitute the following dimensionless variables:

$$
\begin{aligned}
& \mathrm{t}=\frac{\mathrm{v} \mathrm{t}^{\prime}}{\mathrm{r}_{0}^{2}}, \mathrm{X}=\frac{\mathrm{x}}{\mathrm{r}_{0}} \mathrm{Gr}^{-1}, \mathrm{R}=\frac{\mathrm{r}}{\mathrm{r}_{0}}, \mathrm{U}=\frac{\mathrm{ur}_{0} \mathrm{Gr}^{-1}}{\mathrm{v}}, \mathrm{V}=\frac{\mathrm{vr_{0 }}}{\mathrm{v}} \\
& \mathrm{T}=\frac{\mathrm{T}^{\prime}-\mathrm{T}_{\infty}^{\prime}}{\mathrm{T}_{\mathrm{w}}^{\prime}-\mathrm{T}_{\infty}^{\prime}}, \quad C=\frac{C^{\prime}-C_{\infty}^{\prime}}{C_{w}^{\prime}-C_{\infty}^{\prime}}, \quad \mathrm{Gr}=\frac{\mathrm{g} \beta \mathrm{r}_{0}^{3}\left(\mathrm{~T}_{\mathrm{w}}^{\prime}-\mathrm{T}_{\infty}^{\prime}\right)}{v^{2}}
\end{aligned}
$$

into Equations (1), (2), (4) and (7) to obtain the following dimensionless equations:

$$
\begin{aligned}
& \frac{\partial}{\partial X}(R U)+\frac{\partial}{\partial R}(R V)=0 \\
& \frac{\partial U}{\partial t}+U \frac{\partial U}{\partial X}+V \frac{\partial U}{\partial R}=\frac{1}{R} \frac{\partial}{\partial R}\left(R \frac{\partial U}{\partial R}\right)+T+N C-M U, \\
& \frac{\partial T}{\partial t}+U \frac{\partial T}{\partial X}+V \frac{\partial T}{\partial R}=\frac{1}{\operatorname{Pr}}\left(1+\frac{4}{3 R^{*}}\right) \frac{1}{R} \frac{\partial}{\partial R}\left(R \frac{\partial T}{\partial R}\right)+D u \frac{1}{R} \frac{\partial}{\partial R}\left(R \frac{\partial C}{\partial R}\right), \\
& \frac{\partial C}{\partial t}+U \frac{\partial C}{\partial X}+V \frac{\partial C}{\partial R}=\frac{1}{S c} \frac{1}{R} \frac{\partial}{\partial R}\left(R \frac{\partial C}{\partial R}\right)-\gamma C+S r \frac{1}{R} \frac{\partial}{\partial R}\left(R \frac{\partial T}{\partial R}\right),
\end{aligned}
$$

where $\gamma=\frac{k_{c} r_{0}^{2}}{v}, \quad D u=\frac{D_{m} k_{T}}{v C_{S} C_{P}} \frac{C_{w}^{\prime}-C_{\infty}^{\prime}}{T_{w}^{\prime}-T_{\infty}^{\prime}}$ and $S r=\frac{D_{m} k_{T}}{v T_{m}} \frac{T_{w}^{\prime}-T_{\infty}^{\prime}}{C_{w}^{\prime}-C_{\infty}^{\prime}}$ are the chemical reaction parameter and Soret number and Dufour number, respectively.

The corresponding dimensionless boundary conditions can be written as $t=0: U=V=0, T=T_{\infty}, C=C_{\infty}$

$$
\mathrm{t}>0: \begin{cases}\mathrm{U}=\mathrm{V}=0, \mathrm{~T}=0, \mathrm{C}=0 & \text { at } \mathrm{X}=0 \\ \mathrm{U}=\mathrm{V}=0, \mathrm{~T}=1, \mathrm{C}=1 & \text { at } \mathrm{R}=1, \mathrm{X}>0 \\ \mathrm{U}=0, \mathrm{~T}=0, \mathrm{C}=0 & \text { at } \mathrm{R} \rightarrow \infty, \mathrm{X}>0\end{cases}
$$

Of special significance for this type of flow and heat and mass transfer situation are the local skin-friction coefficient $C_{f}$, the local rate of heat transfer or Nusselt number $\mathrm{Nu}_{\mathrm{x}}$ and the local rate of mass transfer or Sherwood number $S h_{x}$. These physical quantities are defined in dimensionless form, respectively, as follows:

$$
\begin{aligned}
& C_{f}=\frac{C_{f}^{*}}{G r}=\left(\frac{\partial U}{\partial R}\right)_{R=1} \\
& \mathrm{Nu}_{\mathrm{x}}=\frac{\mathrm{Nu}_{x}^{*}}{G r}=-X\left(1+\frac{4}{3 R^{*}}\right)\left(\frac{\partial T}{\partial R}\right)_{R=1} \\
& \mathrm{Sh}_{\mathrm{x}}=\frac{\mathrm{Sh}_{x}^{*}}{G r}=-X\left(\frac{\partial C}{\partial R}\right)_{R=1}
\end{aligned}
$$

\section{Solution Technique}

The unsteady non-linear coupled equations (10)-(13) subject to the initial and boundary conditions (14) are solved by using an explicit finite-difference scheme. The steady-state condition is attained when $\partial u / \partial t, \partial T / \partial t$ and $\partial C / \partial t$ approach zero in the unsteady-state problem. It is assumed that the length of the plate is $X_{\max }=1$ units and the boundary-layer thickness is $R_{\max }=40$ units. Let $u^{\prime}, v^{\prime}, T^{\prime}$ and $C^{\prime}$ denote the values of $u, v, T$ and $C$ at the end of each time step. The approximate set of the finite-difference equations corresponding to Equations (10)-(13) are:

$$
R(j)\left(\frac{U_{i, j}^{\prime}-U_{i-1, j}^{\prime}}{\Delta X}\right)+R(j)\left(\frac{V_{i, j}^{\prime}-V_{i, j-1}^{\prime}}{\Delta R}\right)+V^{\prime}(i, j)=0
$$




$$
\begin{aligned}
& \left(\frac{U_{i, j}^{\prime}-U_{i, j}}{\Delta t}\right)+U_{i, j}\left(\frac{U_{i, j}-U_{i-1, j}}{\Delta X}\right)+V_{i, j}\left(\frac{U_{i, j+1}-U_{i, j}}{\Delta R}\right)=T_{i, j}^{\prime}+N C_{i, j}^{\prime}+ \\
& \frac{1}{R(j)}\left(\frac{U_{i, j+1}-U_{i, j}}{\Delta R}\right)+\left(\frac{U_{i, j+1}-2 U_{i, j}+U_{i, j-1}}{(\Delta R)^{2}}\right)-M U_{i, j} \\
& \left(\frac{T_{i, j}^{\prime}-T_{i, j}}{\Delta t}\right)+U_{i, j}\left(\frac{T_{i, j}-T_{i-1, j}}{\Delta X}\right)+V_{i, j}\left(\frac{T_{i, j+1}-T_{i, j}}{\Delta R}\right)=\frac{1}{\operatorname{Pr}}\left(1+\frac{4}{3 R}\right)\left(\begin{array}{l}
\frac{1}{R(j)}\left(\frac{T_{i, j+1}-T_{i, j}}{\Delta R}\right)+ \\
\frac{T_{i, j+1}-2 T_{i, j}+T_{i, j-1}}{(\Delta R)^{2}}
\end{array}\right) \\
& +D u\left(\frac{1}{R(j)}\left(\frac{C_{i, j+1}-C_{i, j}}{\Delta R}\right)+\left(\frac{C_{i, j+1}-2 C_{i, j}+C_{i, j-1}}{(\Delta R)^{2}}\right)\right) \\
& \left(\frac{C_{i, j}^{\prime}-C_{i, j}}{\Delta t}\right)+U_{i, j}\left(\frac{C_{i, j}-C_{i-1, j}}{\Delta X}\right)+V_{i, j}\left(\frac{C_{i, j+1}-C_{i, j}}{\Delta R}\right)=\frac{1}{S c}\left(\begin{array}{l}
\frac{1}{R(j)}\left(\frac{C_{i, j+1}-C_{i, j}}{\Delta R}\right)+ \\
\left(\frac{C_{i, j+1}-2 C_{i, j}+C_{i, j-1}}{(\Delta R)^{2}}\right)
\end{array}\right) \\
& +S r\left(\frac{1}{R(j)}\left(\frac{T_{i, j+1}-T_{i, j}}{\Delta R}\right)+\left(\frac{T_{i, j+1}-2 T_{i, j}+T_{i, j-1}}{(\Delta R)^{2}}\right)\right)
\end{aligned}
$$

where $(i, j)$ represent the grid points in the $\mathrm{X}$ and $\mathrm{R}$ directions, respectively. The coefficients $U_{i, j}$ and $V_{i, j}$ are treated as constants during any one time-step. Then, at the end of any time step $\Delta t$, the new velocity components U'and $\mathrm{V}^{\prime}$, the new temperature $T^{\prime}$ and the new concentration $C^{\prime}$ at all interior grid points may be obtained by successive applications of Equations (18)-(21).

The velocity, temperature and concentration profiles were calculated at various dimensionless times. The region of integration is considered as a rectangle with sides $X_{\max }(=1)$ and $R_{\max }(=40)$ where $R_{\max }$ corresponds to $R=\infty$ which lies very well outside the momentum, thermal and concentration boundary layers. After performing few tests on sets of mesh sizes to access grid independence, the time and spatial step sizes $\Delta t=0.001, \Delta x=0.033$ and $\Delta \mathrm{R}=0.4$ were found to give accurate results. The results are presented in the next section with a view to isolate the effect of each individual parameter. The complete results for $t=1,2, \ldots .15$ show little or no change in $U, V, T$ and $C$. The value $t=15$ is used in most of the figures and is considered as representing the steady-state condition. A comparison of the present results with the results previously reported by Chen and Yuh (1980) is shown in Figure 1. This comparison shows that the results are in excellent agreement. This lends confidence in the accuracy of the numerical results to be reported in the next section.

\section{Results and Discussion}

In this section, representative numerical results are displayed with the help of graphical illustrations. Computations were carried out for various values of physical parameters such as the magnetic field parameter $M$, chemical reaction parameter $\gamma$, Schmidt number $S c$, buoyancy ratio $N$, Dufour number $D u$, thermal radiation parameter $\mathrm{R}^{*}$ and the Prandtl number $\operatorname{Pr}$. Selective steady-state results are presented in Figs. 2-21 while some unsteady results are presented in Figs. 22-27.

Figures 2-4 present the effects of the magnetic field parameter $M$ on the steady-state velocity, temperature and concentration profiles, respectively. Application of a magnetic field has the tendency to slow down the movement of the fluid causing its velocity to decrease as the magnetic field parameter increases. In addition, this decrease in the flow movement as the magnetic field parameter increases is accompanied by increases in both the temperature and concentration profiles. These behaviors are clearly displayed in Figures 2-4. 


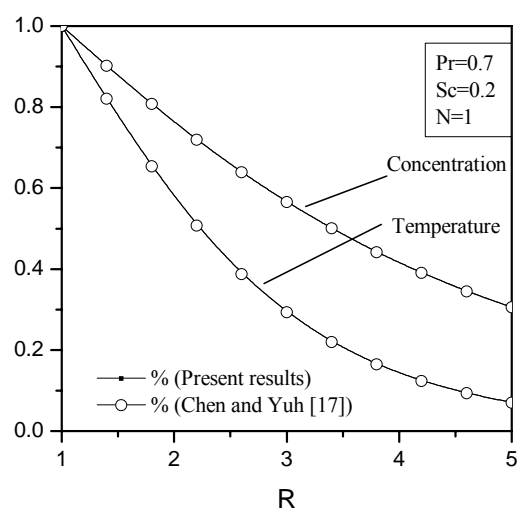

Fig. 1: Comparison of temperature and concentration profiles with Chen and Yuh (1980)

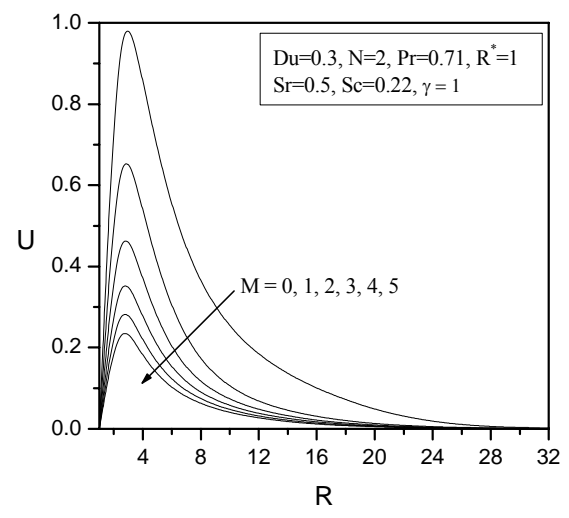

Fig. 2: Effects of magnetic field parameter on the velocity profiles

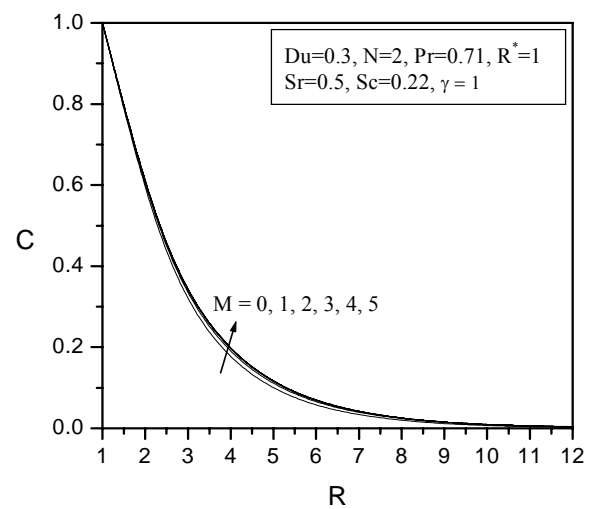

Fig. 4: Effects of magnetic field parameter on the concentration profiles

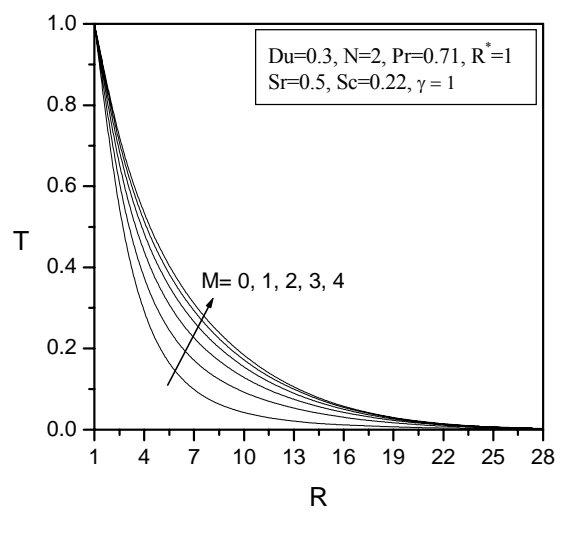

Fig. 3: Effects of magnetic field parameter on the temperature profiles

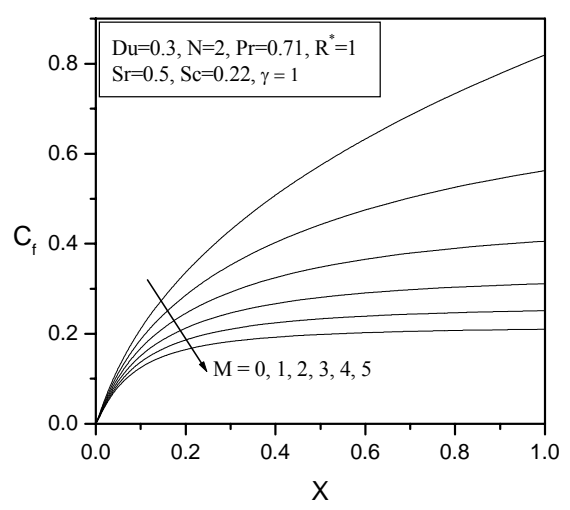

Fig. 5: Effects of magnetic field parameter on the local skin-friction coefficient

Figures 5-7 illustrate the influence of the magnetic field parameter $\mathrm{M}$ on the axial distributions of the local skinfriction coefficient $\mathrm{C}_{\mathrm{f}}$, local Nusselt number $\mathrm{Nu}$ and the local Sherwood number Sh, respectively. It is predicted that all of $\mathrm{C}_{\mathrm{f}}, \mathrm{Nu}$ and $\mathrm{Sh}$ increases with increasing values of the axial distance $\mathrm{X}$. Also, as the magnetic field 
parameter $\mathrm{M}$ increases, all of the local skin-friction coefficient, local Nusselt number $\mathrm{Nu}$ and the local Sherwood number decrease as evident from Figs. 5-7.

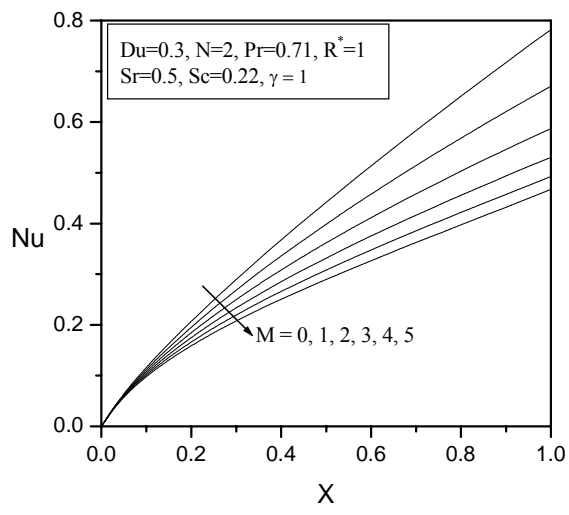

Fig. 6: Effects of magnetic field parameter on the local Nusselt number

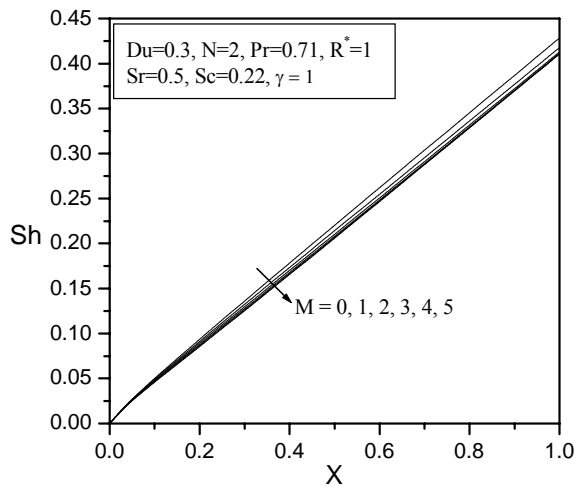

Fig. 7: Effects of magnetic field parameter on the local Sherwood number

Figures 8-10 show the influence of the chemical reaction parameter $\gamma$ and the Schmidt number Sc on the steadystate velocity, temperature and concentration profiles in the boundary layer, respectively. Increasing the chemical reaction parameter produces a decrease in the species concentration. In turn, this causes the concentration buoyancy effects to decrease as $\gamma$ increases. Consequently, less flow is induced along the cylinder resulting in decreases in the fluid velocity in the boundary layer. Also, increasing the chemical reaction parameter leads to an increase in the temperature profiles. In addition, increasing the Schmidt number Sc causes decreases in both the velocity and concentration profiles while the temperature profiles increase. Furthermore, the concentration boundary layer thickness decreases as either $\gamma$ or Sc increases. These behaviors are clearly depicted in Figs. 8-10.

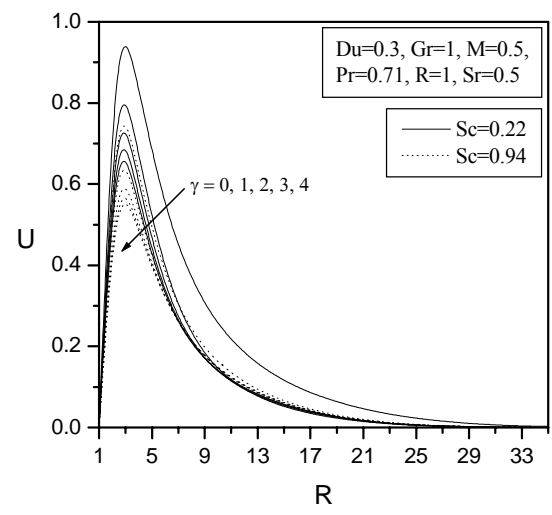

Fig. 8: Effects of chemical reaction parameter on the velocity profiles

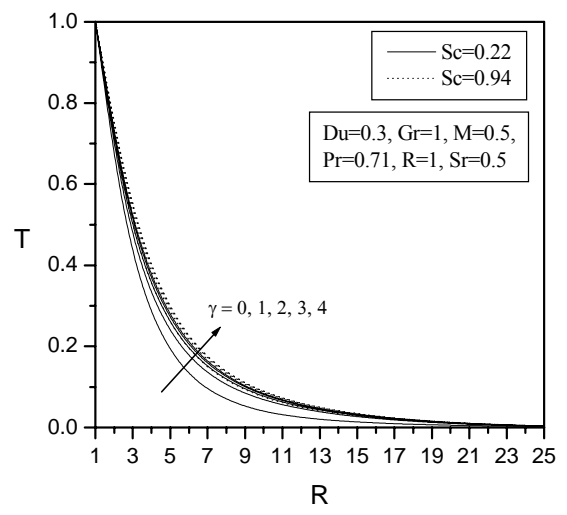

Fig. 9: Effects of chemical reaction parameter on the temperature profiles

Figures 11-13 elucidate the influence of the chemical reaction parameter $\gamma$ and the Schmidt number Sc on the axial distributions of the local skin-friction coefficient $\mathrm{C}_{\mathrm{f}}$, local Nusselt number $\mathrm{Nu}$ and the local Sherwood number Sh, respectively. The local skin-friction coefficient and the local Nusselt number are predicted to decrease as either of the Schmidt number or the chemical reaction parameter increases. On the other hand, the local Sherwood number is predicted to increase as either of the Schmidt number or the chemical reaction parameter increases. 


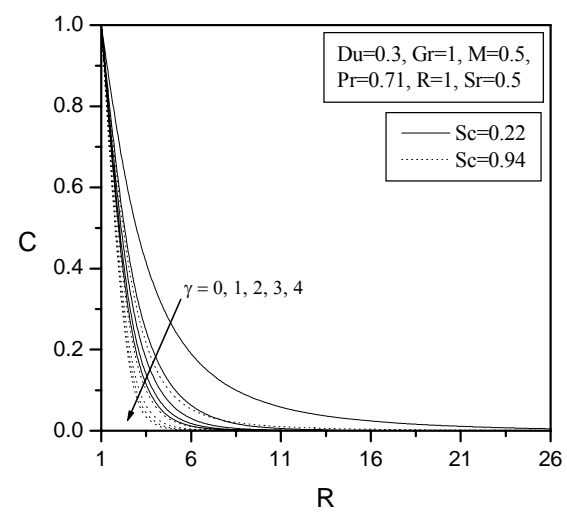

Fig. 10: Effects of chemical reaction parameter on the concentration profiles

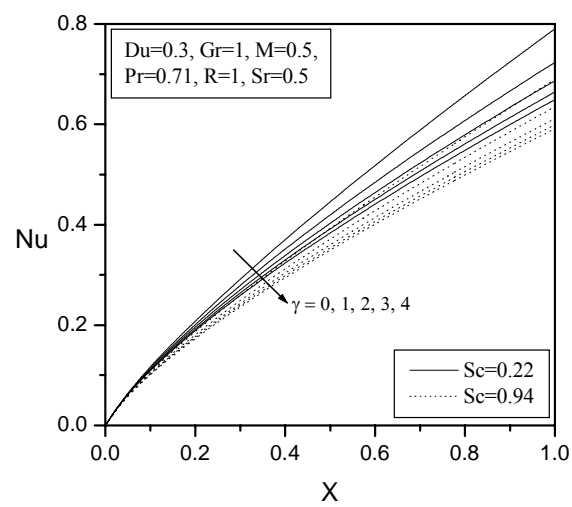

Fig. 12: Effects of the chemical reaction parameter and Schmidt number on the local Nusselt number

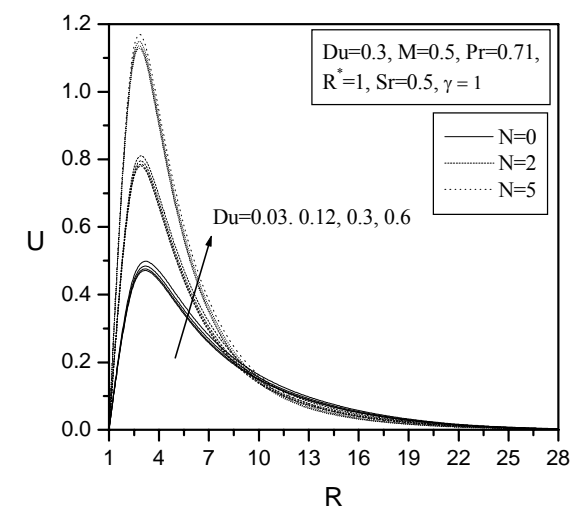

Fig. 14: Effects of Dufour number and buoyancy ratio on the velocity profiles

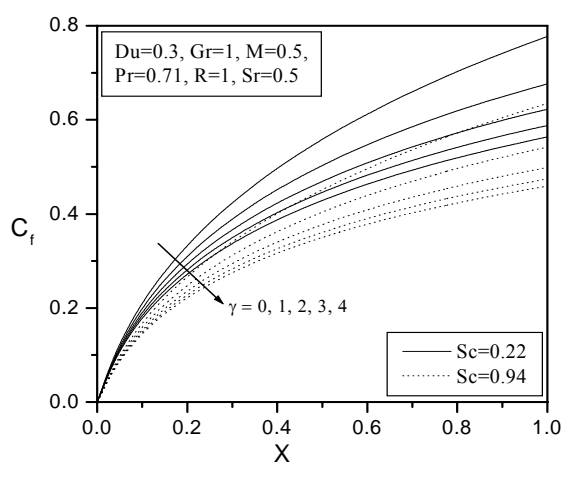

Fig. 11: Effects of chemical reaction parameter and Schmidt number on the local skin-friction coefficient

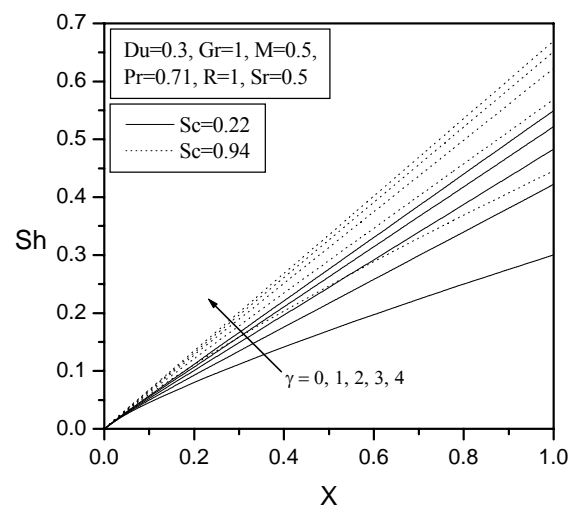

Fig. 13: Effects of the chemical reaction parameter and Schmidt number on the local Sherwood number

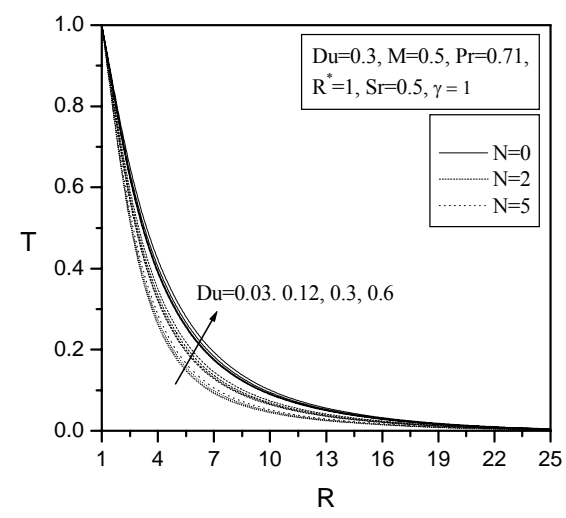

Fig. 15: Effects of Dufour number and buoyancy ratio on the temperature profiles

Figures 14 and 15 show the effects of Dufour number $D u$ and the buoyancy ratio $N$ on the velocity and temperature profiles, respectively. Increasing the Dufour number has the tendency to increase the fluid 
temperature. By virtue of the thermal buoyancy effect, this in turn, induces more flow along the cylinder represented by the increases in the fluid velocity. In addition, as the buoyancy ratio parameter increases, the fluid velocity increases while the fluid temperature decreases. All these features are shown in Figs. 14 and 15 . It should be mentioned that changing the Soret number Sr produced small changes in the results. For this reason, no results are presented.

Figures 16 and 17 illustrate the effects of the Dufour number Du and the buoyancy ratio parameter $\mathrm{N}$ on the axial distributions of the local skin-friction coefficient $\mathrm{C}_{\mathrm{f}}$ and the local Nusselt number Nu, respectively. It is seen that the local skin-friction coefficient increases with the increases in both the Dufour number and the buoyancy ratio parameter. However, the local Nusselt number or local rate of heat transfer increases as the buoyancy ratio parameter increases while it decreases as the Dufour number increases.

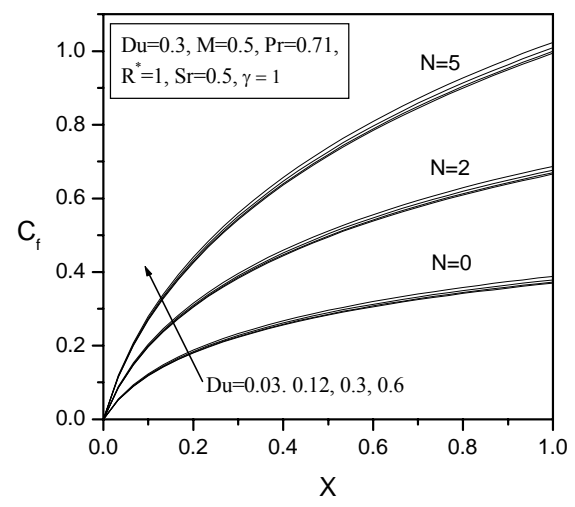

Fig. 16: Effects of Dufour number and buoyancy ratio on the local skin-friction coefficient

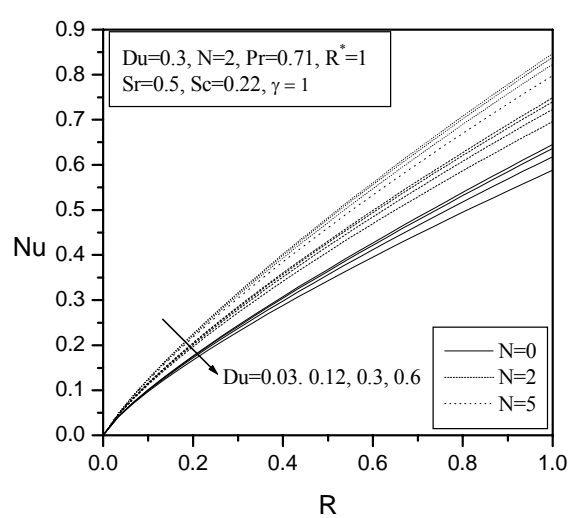

Fig. 17: Effects of Dufour number and buoyancy ratio on the local Nusselt number

Figures 18 and 19 display the effects of the thermal radiation parameter $R^{*}$ and the Prandtl number on the velocity and temperature profiles in the boundary layer, respectively. Decreasing the thermal radiation parameter $\mathrm{R}^{*}$ (i.e. increasing radiation effects) produces significant increase in the thermal state of the fluid causing its temperature to increase. This increase in the fluid temperature induces through the effect of thermal buoyancy more flow in the boundary layer causing the velocity of the fluid there to increase. In addition, as the Prandtl number increases, the fluid temperature and its thermal boundary layer decrease causing less induced flow represented by decreased values in the fluid velocity.

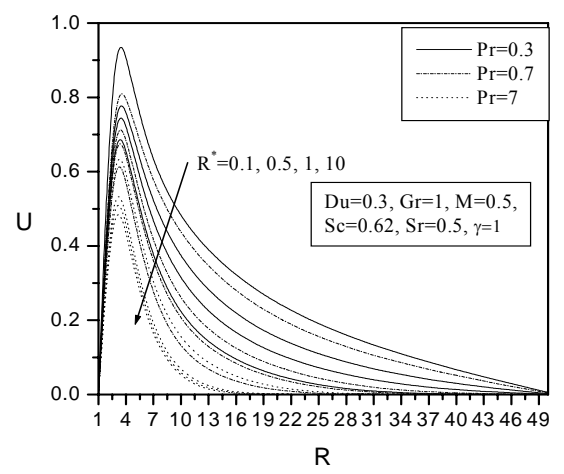

Fig. 18: Effects of radiation parameter and Prandtl number on the velocity profiles

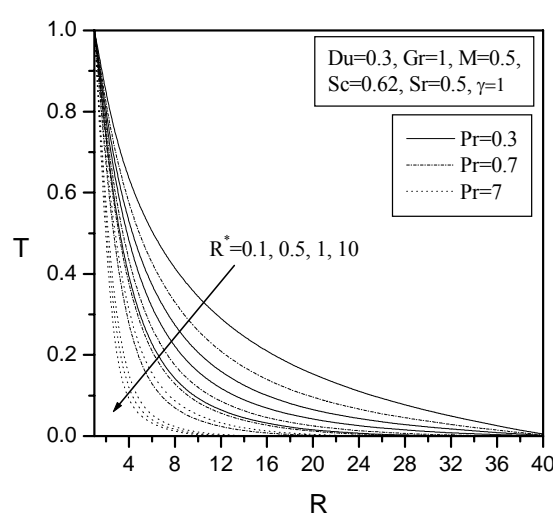

Fig. 19: Effects of radiation parameter and Prandtl number on the temperature profiles

Figures 20 and 21 show the effects of the radiation parameter with Prandtl number on the axial distributions of the local skin-friction coefficient $\mathrm{C}_{\mathrm{f}}$ and the rate of heat transfer or Nusselt number $\mathrm{Nu}$, respectively. It is observed that as radiation parameter $\mathrm{R}^{*}$ increases, the local skin-friction coefficient and the local Nusselt 
number decrease. Moreover, the local skin-friction coefficient decreases while the local Nusselt number increases as the Prandtl number increases. In general, in these figures, the values of $\mathrm{C}_{\mathrm{f}}$ and $\mathrm{Nu}$ increase with increasing values of $X$.

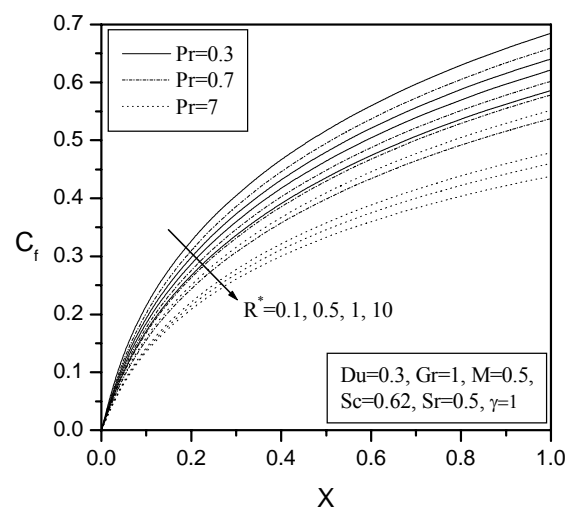

Fig. 20: Effects of radiation parameter and Prandtl number on the local skin-friction coefficient

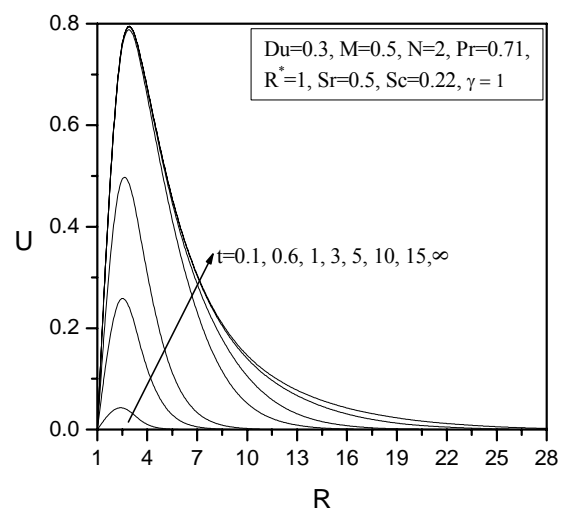

Fig. 22: Development of the velocity profiles with time

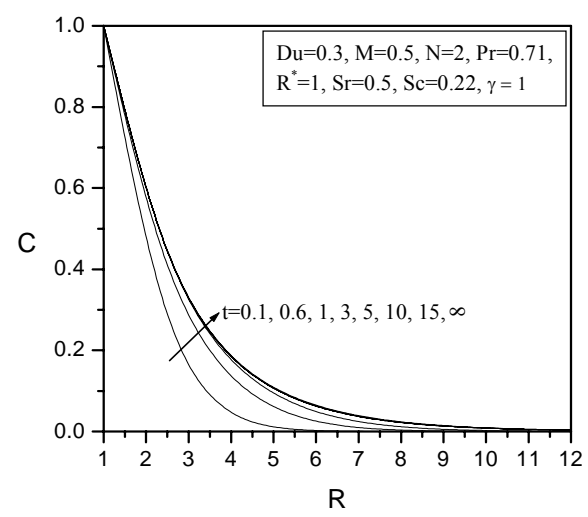

Fig. 24: Development of the concentration profiles with time

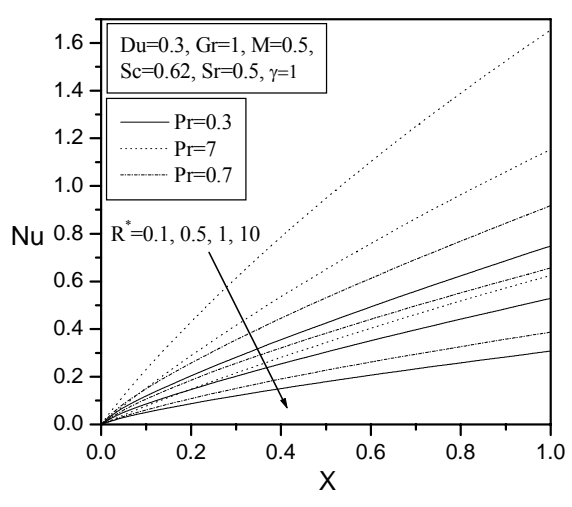

Fig. 21: Effects of radiation parameter and Prandtl number on the local Nusselt number

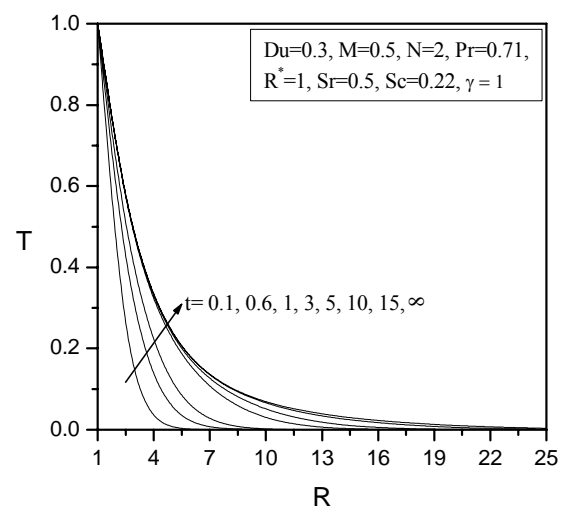

Fig. 23: Development of the temperature profiles with time

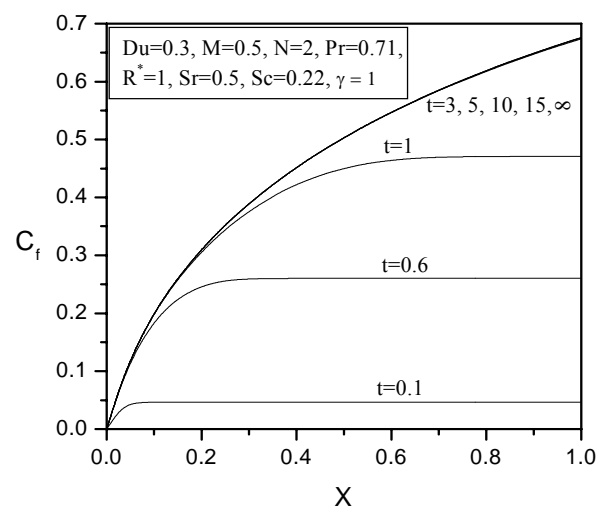

Fig. 25: Development of the local skin-friction coefficient with time 
Figures 22-24 display the development of the fluid velocity, temperature and solute concentration profiles with the dimensionless time $t$, respectively. As expected, the distributions of all of the velocity, temperature and concentration as well as their boundary-layer thicknesses increase as time progresses until they reach their steady-state values at $\mathrm{t}=\infty$. It should be noted that there is no difference between the results at $\mathrm{t}=15$ and $\mathrm{t}=\infty$ which means that the steady state conditions are essentially reached at $\mathrm{t}=15$.

Figures 25-27 depict the axial distributions of the local skin-friction coefficient, local Nusselt number and the local Sherwood number at various dimensionless times ranging from unsteady conditions to steady-state conditions. It is predicted that the local skin-friction coefficient increases while the local Nusselt and Sherwood numbers decrease at $t$ increases.

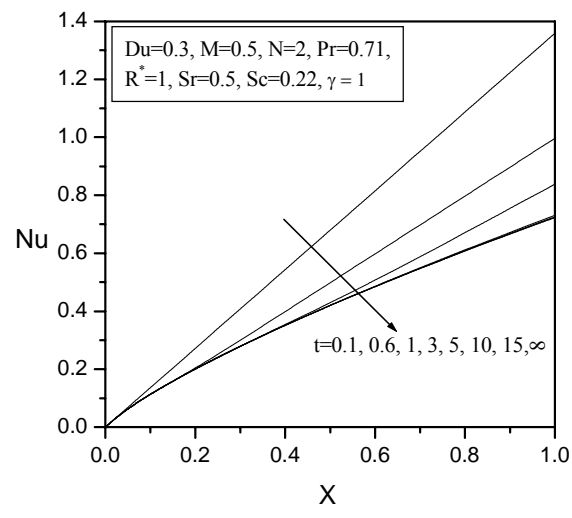

Fig. 26: Development of the local Nusselt number with time

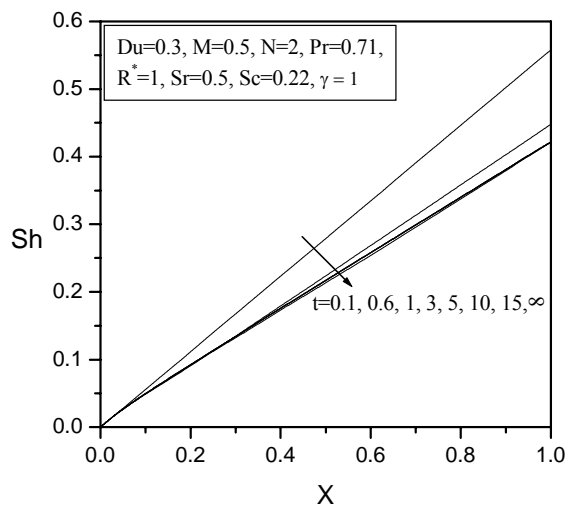

Fig. 27: Development of the local Sherwood number with time

\section{Conclusions}

The problem of double diffusive unsteady natural convection MHD flow along a vertical cylinder in the presence of relevant physical effects such as homogeneous chemical reaction, thermal radiation and Soret and Dufour effects was investigated. Both the cylinder wall temperature and concentration were assumed to be constant. Comparisons with previously published work were made and the results were found to be in excellent agreement. The governing equations for this problem were developed and non-dimensionalized and the resulting equations were then solved numerically by an explicit finite-difference scheme. It was found that, in general, the local skin-friction coefficient increased as either of the buoyancy ratio or the Dufour number increased and it decreased as a result of increasing either of the magnetic field parameter, thermal radiation parameter, Prandtl number, Schmidt number or the chemical reaction parameter. In addition, the local Nusselt number was predicted to increase due to increases in either of the Prandtl number or the buoyancy ratio while it decreased as either of the magnetic field parameter, thermal radiation parameter, Dufour number, chemical reaction parameter or the Schmidt number increased. Furthermore, the local Sherwood number was predicted to decreases as the magnetic field parameter increased while it increased as a result of increasing either of the Prandtl number, chemical reaction parameter or the Schmidt number. It is hoped that the present work will serve as a vehicle for understanding more complex problems involving the various physical effects investigated in the present problem.

\section{References}

Bottemanne, G.A. (1972): Experimental Results of Pure and Simultaneous Heat and Mass Transfer by Free Convection about A Vertical Cylinder for $\mathrm{Pr}=0.7$ and $\mathrm{Sc}=0.63$, Appl. Sci. Res., vol. 25, pp. 372-382.

doi:10.1007/BF00382310

Chamkha, A.J., Ben-Nakhi, A. (2008): MHD Mixed Convection-Radiation Interaction along A Permeable Surface Immersed in A Porous Medium in The Presence of Soret and Dufour's Effect, Heat Mass Transfer, vol. 44, pp. 845-856. doi:10.1007/s00231-007-0296-x

Chapman, S., Cowling T.G. (1952): The Mathematical Theory of Non-Uniform Gases, Cambridge, U.K: Cambridge University Press. 
Chen, T.S., Yuh, C.F. (1980): Combined Heat and Mass Transfer in Natural Convection along A Vertical Cylinder, Int. J. Heat Mass Transfer, vol. 23, pp. 451- 461. doi:10.1016/0017-9310(80)90087-3

doi:10.1016/0017-9310(80)90094-0

Chen, J.L.S. (1983): Natural Convection from Needles with Variable Wall Heat Flux, J. Heat Transfer, vol. 105, pp. 403-406. doi:10.1115/1.3245594

Duwairi, H.M., Damseh, R.A. (2004): Magnetohydrodynamic Natural Convection Heat Transfer from Radiate Vertical Porous Surfaces, Heat Mass Transfer, vol. 40, pp. 787-792. doi:10.1007/s00231-003-0476-2

Duwairi, H.M., Damseh R.A. (2004): MHD-Buoyancy Aiding and Opposing Flows with Viscous Dissipation Effects from Radiate Vertical Surfaces, Can J. Chem. Eng., vol. 82, pp. 613-618. doi:10.1002/cjce.5450820322

Ganesan, P.G., Rani, P.H. (1999): Unsteady Free Convection on A Vertical Cylinder with Variable Heat and Mass Flux, Heat and Mass Transfer, vol. 35, pp. 259-265. doi:10.1007/s002310050322

Ganesan, P.G., Rani, P.H. (2000): Unsteady Free Convection MHD Flow past A Vertical Cylinder with Heat and Mass Transfer, Int. J. Therm. Sci., vol. 39, pp. 265-272. doi:10.1016/S1290-0729(00)00244-1

Ganesan, P.G., longathan, P. (2001): Unsteady Natural Convective Flow Past A Moving Vertical Cylinder with Heat and Mass Transfer, Heat Mass Transfer, vol. 37, pp. 59-65. doi:10.1007/s002310000128

Heckel, J.J., Chen, T.S., Armaly, B.F. (1989): Natural Convection along Slender Vertical Cylinders with Variable Surface Heat Flux, ASME J. Heat Transfer, vol. 111, pp. 1108-1111. doi:10.1115/1.3250781

Hirshfelder, J.O., Curtis, C.F., Bird, R.B. (1954): Molecular Theory of Gases and Liquids, New York: Wiley. Hossain, M.A., Takhar, H.S. (1996): Radiation Effects on Mixed Convection along A Vertical Plate with Uniform Surface Temperature, Heat Mass Transfer, vol. 31, pp. 243-248. doi:10.1007/BF02328616

Hossain, M.A., Alim, M.A., Rees DAS. (1999): The Effect of Radiation on Free Convection from A Porous Vertical Plate, Int. J. Heat Mass Transfer, vol. 42, pp. 181-191. doi:10.1016/S0017-9310(98)00097-0

Kafoussias, N.G., Williams, E.W. (1995): Thermal-Diffusion and Diffusion-Thermo Effects on Mixed FreeForced Convective and Mass Transfer Boundary Layer Flow with Temperature Dependent Viscosity, Int. J. Eng. Sci., vol. 33, pp. 1369-84. doi:10.1016/0020-7225(94)00132-4

Kandasamy, R., Periasamy, K., Sivagnanam K.K., Prabhu, (2005): Chemical Reaction, Heat and Mass Transfer on MHD Flow over A Vertical Stretching Surface with Heat Source and Thermal Stratification Effects, Int. J. Heat Mass Transferm vol. 48, pp. 4557-4561. doi:10.1016/j.ijheatmasstransfer.2005.05.006

Kandasamy, R., Periasamy, K., Sivagnana, K.K. Prabhu (2005): Effect of Chemical Reaction, Heat and Mass Transfer along A Wedge With Heat Source and Concentration in The Presence of Suction or Injection, Int. J. Heat Mass Transfer, vol. 48, pp. 1388-1394. doi:10.1016/j.ijheatmasstransfer.2004.10.008

Seddeek, M.A. (2001): Thermal Radiation and Buoyancy Effects on MHD Free Convection Heat Generation Flow over An Accelerating Permeable Surface with Temperature Dependent Viscosity, Can. J. Phys., vol. 79, pp. 725-732. doi:10.1139/p01-044

Seddeek, M.A., Darwish, A.A., Abdelmeguid, M.S. (2007): Effect of Chemical Reaction and Variable Viscosity on Hydromagnetic Mixed Convection Heat and Mass Transfer for Hiemenz Flow through Porous Media with Radiation, Commun. Nonlinear Sci. Numer. Simul., vol. 12, pp. 195-213. doi:10.1016/j.cnsns.2006.02.008

Seddeek, M.A., Salem, A.M. (2007): The Effect of An Axial Magnetic Field on The Flow and Heat Transfer about A Fluid Underlying The Axisymmetric Spreading Surface with Temperature Dependent Viscosity and Thermal Diffusivity, Comput. Mech., vol. 39, 401-408. doi:10.1007/s00466-006-0038-9

Seddeek, M.A., Faiza, A.S. (2007): The Effects of Temperature Dependent Viscosity and Thermal Conductivity on Unsteady MHD Convective Heat Transfer Past A Semi-Infinite Vertical Porous Moving Plate with Variable Suction, Comput. Mater. Sci., vol. 40, pp. 186-192. doi:10.1016/j.commatsci.2006.11.012

Sparrow, E.M., Cess, R.D. (1962): Radiation Heat Transfer, Hemisphere, Augment Edition. Sparrow, E.M., Minkowycz, W.J., Eckert, E.R.G. (1964): Diffusion-Thermo Effects in Stagnation-Point Flow of Air With Injection of Gases of Various Molecular Weights into The Boundary Layer, AIAA J., vol. 2, pp. 652 659. doi:10.2514/3.2401 